\title{
Infant-mother attachment security, contextual risk, and early development: A moderational analysis
}

\author{
JAY BELSKY ${ }^{a}$ AND R. M. PASCO FEARON ${ }^{b}$ \\ ${ }^{a}$ Birkbeck University of London; and ${ }^{b}$ University of London
}

\begin{abstract}
In light of evidence that the effects of attachment security on subsequent development may be contingent on the social context in which the child continues to develop, we examined the effect of attachment security at age 15 months, cumulative contextual risk from 1 to 36 months, and the interaction of attachment and cumulative risk to predict socioemotional and cognitive linguistic functioning at age 3 years, using data from the National Institute of Child Health and Human Development Study of Early Child Care. Results indicated that early attachment predicts both socioemotional development and language skills, but not cognitive functioning as indexed by a measure of school readiness, and that the effect of attachment on socioemotional development and expressive language varied as a function of social-contextual risk. Insecure-avoidant infants proved most vulnerable to contextual risk, not children classified as secure or insecure more generally, although in one instance security did prove protective with respect to the adverse effects of cumulative contextual risk. Findings are discussed in terms of risk and resilience and in light of the probabilistic nature of the relation between early attachment and later development.
\end{abstract}

It has been almost 25 years since the first empirical tests of theoretical propositions regarding the developmental sequelae of individual differences in attachment security appeared in the literature. Results from scores of studies have led many developmentalists to argue that individual differences in patterns of attachment have important implications for understanding normal and disordered social and emotional development (e.g., Belsky \& Nezworksi, 1988; Rutter \& Sroufe, 2000; Sroufe, Carlson, Levy, \& Egeland, 1999). As the scope of inquiry has grown, so has the breadth

The research described herein was supported by a cooperative agreement with the National Institute of Child Health and Human Development (U10-HD25420). The authors express their appreciation to all collaborating investigators of the NICHD Study of Early Child Care.

Address correspondence and reprint requests to: Jay Belsky, Institute for the Study of Children, Families and Social Issues, Birkbeck University of London, 7 Bedford Square, London WC1B 3RA, UK; E-mail: j.belsky@ bbk.ac.uk. of developmental outcomes to which early attachment has been linked. This led Sroufe (1988) to wonder whether investigators examining the developmental sequelae of attachment security have cast the net too widely, endeavoring to link early attachment with domains of development that there seems little theoretical reason to believe individual differences in security should be related to. The fact that the domain in question that Sroufe (1988) cites, namely general cognitive ability, has been found in a meta-analysis of 12 studies $(n=514)$ to be related to attachment in only a limited manner $(r=.09)$ would seem to buttress his claim (van Ijzendoorn, Dijkstra, \& Bus, 1995).

However, other findings from the same meta-analysis raise the prospect that the outcomes associated with attachment may not be as narrow as might have been anticipated. This is because van Ijzendoorn et al. (1995) reported a rather substantial relation between attachment and language ability $(r=.28)$ on 
the basis of 303 cases drawn from seven investigations. Such findings appear consistent with what Belsky and Cassidy (1994, see figure 16.1) characterized as a domain-general perspective on the sequelae of attachment, in contrast to a domain-specific approach, which stipulates more restricted influence of attachment on socioemotional developmental outcomes. The fact that language is a particularly social cognitive ability may explain why it is related to early attachment whereas general cognitive ability is not. Alternatively, the third-variable model outlined by Belsky and Cassidy (1994) could also account for the language results under consideration, in that attachment may predict language because it is predicted by social contextual factors, which themselves predict language competence.

In light of the results of past research, effectively summarized in the van Ijzendoorn et al. (1995) investigation, we consider in this inquiry, which is focused on the developmental sequelae of attachment security, measures of cognitive and language development and measures of early social functioning as developmental outcomes to be related to early attachment. By proceeding in this manner, we explore the boundaries of attachment. The aforementioned meta-analytic results lead to the prediction that an index of school readiness, considered to reflect general cognitive ability, will prove unrelated to attachment, whereas assessments of language ability will be related to attachment. The design of this study also enables us to determine whether any detected effects of infant-mother attachment on 3-year functioning are an artifact of contextual risk, a possibility not considered in the van Ijzendoorn et al. (1995) meta-analysis.

Although it is clear that links between early attachment and later development have been discerned much more consistently with respect to socioemotional than cognitive or linguistic functioning (for review, see Colin, 1996), several reviews of the literature make clear that anticipated associations have emerged with less uniformity than is often suggested by discussions of the developmental significance of early attachment for later development (Belsky \& Cassidy, 1994; Greenberg, 1999). The fact that associations between at- tachment and later socioemotional adaptation have not always emerged in relevant studies does not mean, however, that the evidence is wildly inconsistent with respect to the sequelae of attachment. This is because the inconsistency across studies reflects the failure to discern developmental advantages for children with secure attachment histories $100 \%$ of the time more than it does any apparent benefits of insecure attachment (Belsky \& Cassidy, 1994).

The lack of uniformity in the data base on the sequelae of attachment actually makes sense in light of observations that links between early attachment and later socioemotional functioning are not inevitable (Greenberg, 1999; Sroufe, 1988). In fact, for quite some time now Sroufe and his collaborators have argued-and found - that the predictive power of attachment is dependent on other experiences in the child's life both within and beyond the mother-child relationship (Erickson, Sroufe, \& Egeland, 1985; Sroufe et al., 1999). Thus, a failure to chronicle simple, direct, relations between attachment security and later development should not, by itself, be regarded as evidence inconsistent with attachment theory, at least if other pertinent factors have not been taken into consideration. When it comes to examining the role of early attachment in predicting later development, it might, therefore, be best to conceptualize the attachment construct in risk- or protective-factor terms (Greenberg, 1999; Sroufe, 1988). Thus, under some conditions, or for some populations, we might expect to discern links between attachment and later development, whereas under other conditions, or for other populations, we might not. Relatedly, we can think in terms of early attachment moderating the effect of contextual risk on subsequent development. Thus, if attachment security functions as a protective factor and/or insecurity functions as a risk factor, we would expect to find that children with secure attachment histories are less adversely affected by contextual risk, whereas children with insecure histories are more adversely affected by such risks.

Two distinct lines of inquiry do suggest that attachment interacts with features of the social context in predicting later development, 
although the nature of the Attachment $\times$ Context interaction revealed by across-study comparisons varies. In research on continuity in internal working models, in which attachment security assessed in the Strange Situation in infancy is used to predict state of mind regarding attachment as assessed by means of the Adult Attachment Interview in late adolescence/early adulthood, evidence of what Belsky, Fish, and Isabella (1991) labeled "lawful discontinuity" emerges. That is, whereas continuity apparently characterizes development under conditions of low risk (Hamilton, 2000; Waters, Merrick, Treboux, Crowell, \& Albersheim, 2000), with early security predicting later autonomous state of mind and early insecurity predicting dismissing and/or preoccupied state of mind, early attachment fails to forecast later internal working models under conditions of high contextual risk hypothesized to deflect early established developmental trajectories (Weinfield, Sroufe, \& Egeland, 2000).

Intriguingly, the interaction of early attachment and contextual risk appears to operate in a decidedly different manner when the outcome to be explained is problem behavior. Instead of prediction obtaining under conditions of low risk, as in the case of state of mind, prediction obtains under conditions of high contextual risk. Thus, whereas investigations of high-risk samples find that insecure infantmother attachment, especially of the insecureavoidant variety, predicts behavior problems in early childhood (Erickson, Sroufe, \& Egeland, 1985; Shaw \& Vondra, 1995) and during the early elementary school years (Munson, McMahon, \& Spieker, 2001; Renken, Egeland, Marvinney, Sroufe, \& Mangelsdorf, 1989), research on low-risk, middle-class samples generally fails to detect such associations (Bates, Maslin, \& Frankel, 1985; Belsky, Hsieh, \& Crnic, 1998; Fagot \& Kavanaugh, 1990).

In light of the variable nature of the interaction of early attachment and contextual risk in predicting later development, a primary goal of this investigation is to further explore these interactive effects in hopes of illuminating risk- and protective-factor processes. Because the developmental outcomes we exam- ine are assessed quite early in life and address behavioral development rather than internal working models during young adulthood, we take our lead from the behavior-problem studies described previously when it comes to hypotheses about moderational effects. This leads us to hypothesize that the predictive power of attachment will be greater under conditions of higher social-contextual risk. That is, the power of early attachment to predict later development may be limited under low-risk conditions, but in contexts of high ecological risk greater evidence of attachment effects will emerge. Or, reframed, attachment security will moderate the effects of social context on development, such that a history of insecurity will amplify the risk associated with contextual risk, whereas a history of security will protect against it.

Having advanced these propositions, we would be remiss if we did not observe that reasoned arguments could be made for just the opposite predictions. For example, only when ecological conditions are supportive of development will early security predict enhanced functioning in the future. This is certainly what the data on the long-term stability of attachment security cited earlier would seem to suggest (Hamilton, 2000; Waters et al., 2000; Weinfield et al., 2000). Ultimately, it is because competing predictions make logical sense that we remain open to the possibility that for different developmental outcomes, different moderational findings could emerge.

When it comes to conceptualizing and measuring contextual risk, we follow the lead of recent investigations that highlight the significance of cumulative risk (e.g., Liaw \& Brooks-Gunn, 1994; Pungello, Kupersmidt, Burchinal, \& Patterson, 1996; Rutter, 1979; Sameroff, Seifer, Baldwin, \& Baldwin, 1993). Researchers adopting this perspective on risk argue that more important than any single risk factor in undermining development is the accumulation of risk factors, which can be quite varied in their nature (Rutter, 2000; Rutter \& Sroufe, 2000; Sameroff, 2000). Evidence consistent with the notion that multiple or cumulative risk is of developmental significance comes from a variety of sources. In work on attachment, Belsky (1996) found that the 
more indicators of risk characterized a father and a family (e.g., negative personality, unhappy marriage), the more likely sons were to develop insecure attachments to their fathers. (For related evidence on mothers, see Belsky \& Isabella, 1988, and Belsky, Rosenberger, \& Crnic, 1995.) With respect to child behavior problems, Rutter, Cox, Tupling, Berger and Yule (1975) reported that the presence of two or more indicators of family adversity were associated with a two- to fourfold increase in problematic outcomes. Data from the Rochester Longitudinal Study also showed that the more risk factors, the greater the prevalence of clinical symptoms in preschoolers (Sameroff, Seifer, Zax, \& Barocas, 1987) and the poorer the mental health of children at 13 and 18 years of age (Sameroff, Bartko, Baldwin, Baldwin, \& Seiffer, 1998; see also Furstenberg, Cook, Eccles, Elder, \& Sameroff, 1999). Also noteworthy, given one focus of the current study on school readiness at age 3 years, is the replicated finding that cumulative contextual risk predicts poor academic achievement during middle childhood and adolescence (Brooks-Gunn, Klebanov, Liaw, \& Duncan, 1995; Furstenberg et al., 1999; Luster \& McAdoo, 1994). In light of these and other recent findings, we conduct our examination of the role of early attachment and contextual risk in predicting child functioning at age 3 years using a cumulative index of risk.

\section{Method}

\section{Participants}

Participants were recruited from 31 hospitals located in or near Little Rock, AR; Irvine, CA; Lawrence, KS; Boston, MA; Philadelphia, PA; Pittsburgh, PA; Charlottesville, VA; Morganton, NC; Seattle, WA; and Madison, WI. During selected 24-hr sampling periods in 1991, 8,986 women giving birth were visited in the hospital. Of these, 5,416 met the eligibility criteria for the study and agreed to be contacted after their return home from the hospital. A subset of this group was selected in accordance with a conditional-random sampling plan that was designed to ensure that recruited families reflected the demographic diversity (economic, educational, and ethnic) of the catchment area at each site. When the infants were 1 month old, 1,364 families (58\% of those contacted) with healthy newborns were enrolled in the study. Of the 1,364 families who took part in the National Institute of Child Health and Human Development (NICHD) Study of Early Child Care, only a subset is reported here.

Missing data. A number of cases were missing attachment data, either because the Strange Situation was not conducted at 15 months $(n=167)$ or because the Strange Situation data was deemed uncodable $(n=48)$. There were thus 1,149 valid Strange Situation assessments available for analysis in the data set. Of those cases with valid Strange Situation data, 1,015 had complete outcome data.

The major source of missing data in relation to the current report was in assessments of social-contextual risk factors, particularly those assessed repeatedly. We chose to balance sample size against data quality by using regression-based missing data estimation on a risk by risk basis, using the Missing Value Analysis procedure of SPSS for Windows Version 9.0. Specifically, we estimated missing data points from nonmissing assessments of the same risk domain only when at least $50 \%$ of the potential data were available. Using these procedures, 946 cases could be included in the current report, complete with data on attachment, contextual risk, and outcome.

Attrition. The sample included in the current analyses was clearly not a random sample from the total data set. In particular, of this analysis sample, 86.7\% were European American (total $n=946$ ), compared with $73.4 \%$ in the sample that was excluded because of missing data (total $n=418 ; \chi^{2}=35.4, p<$ $.0001)$. Table 1 provides data on differences in the remaining psychosocial risk factors between cases excluded and included in the present report. The table clearly indicates that the present sample was, on average, at lower risk, although it is notable that the overlap in ranges between the samples is substantial and the sizes of these biases were consistently 
Table 1. Mean, standard deviation, and range of contextual-risk variable scores for analyzed and excluded samples

\begin{tabular}{|c|c|c|c|c|c|c|c|c|c|}
\hline \multirow[b]{2}{*}{ Social Context } & \multicolumn{3}{|c|}{ Analyzed } & \multicolumn{3}{|c|}{ Excluded $^{a}$} & \multicolumn{3}{|c|}{ Statistics } \\
\hline & Mean & $S D$ & Range & Mean & $S D$ & Range & $t$ & $p$ & $\varepsilon^{2}$ \\
\hline Income to needs ratio & 3.57 & 2.69 & $0-18.7$ & 2.82 & 3.04 & $0-17.7$ & 4.13 & $<.001$ & .013 \\
\hline Social support & 5.00 & 0.56 & $2.7-6.0$ & 4.96 & 0.64 & $2.6-6.0$ & 1.24 & .215 & .001 \\
\hline Depression & 9.13 & 6.22 & $0-37.2$ & 11.21 & 7.68 & $0-41.5$ & 4.80 & $<.001$ & .018 \\
\hline Marital harmony & 5.60 & 1.07 & $1.8-6.2$ & 5.71 & 1.04 & $2.6-6.0$ & 1.52 & .130 & .002 \\
\hline Personality & 17.14 & 10.25 & $14.0-99.0$ & 14.67 & 11.30 & $20.0-97.0$ & 3.65 & $<.001$ & .010 \\
\hline Father home & 0.90 & 0.25 & $0-1$ & 0.63 & 0.45 & $0-1$ & 13.48 & $<.001$ & .126 \\
\hline Parenting stress & 41.16 & 5.96 & $25.2-62.4$ & 42.27 & 6.45 & $27.4-60.8$ & 2.37 & .018 & .005 \\
\hline
\end{tabular}

${ }^{a}$ Excluded sample $n$ ranges from 326 to 200 .

modest, accounting for no more than $1.9 \%$ of the variance $\left(\varepsilon^{2}\right.$ in Table 1$)$ in any one measure. There were also differences in the distribution of attachment classifications (A, B, C, D) between cases included and excluded from the analyses of this report $\left(\chi^{2}=9.9, p=.02\right)$. Specifically, $62.7 \%$ of the analyzed sample $(N=946)$ was classified secure, compared to $57.6 \%$ of the group with missing data $(N=$ 203).

In light of these results, it should be evident that the analyses reported herein examine a somewhat restricted range of several sociodemographic factors and will to some degree underrepresent more socially disadvantaged populations. The likely effect of these sampling biases on our estimates of attachment effects and Risk $\times$ Attachment interactions is difficult to assess, although given the presumed relations between attachment, risk, and outcome it would seem perhaps more likely that sampling biases of this kind would lead to under- not overestimates of reliable associations. Nevertheless, this is something that we cannot demonstrate directly and sampling issues should be considered carefully when interpreting the analyses that follow.

\section{Procedures and measures}

Data for this report were collected through interviews with the mother and/or behavioral assessment of the child at 1, 6, 15, 24, and 36 months of age. Measures are presented according to their function in the analyses, beginning with the assessment of attachment security, followed by measures of contextual risk, before describing the child outcome measures at age 3 years.

Attachment security. Infant-mother attachment security was assessed at 15 months using the Ainsworth and Wittig (1969) Strange Situation procedure. Videotapes of all Strange Situations were coded at a central location by a team of three coders blind to children's childcare status. Each of 1,201 Strange Situations were scored independently by two coders using the standard classifications of secure (B), insecure-avoidant (A), insecure-resistant (C), disorganized (D), and unclassifiable (U). Disagreements were viewed by the group and a code was assigned by consensus. Across all coder pairs, before conferencing, agreement with the five-category classification system was $83 \%(\kappa=.69)$ and agreement for the two-category system (secure/insecure) was $86 \%(\kappa=.70)$. For purposes of this report, only cases classified as A, B, C, and D are included. (For further information on attachment scoring, see NICHD Early Child Care Research Network, 1997.)

Contextual risk. Multiple indicators of contextual risk that have been implicated in past research were available in the NICHD data set. For purpose of this report, nine variables reflective of risk (at one point in time or across multiple time points) were standardized and summed to create an index of cumulative contextual risk.

Two variables reflective of socioeconomic 
risk were included in the composite. An income to needs ratio was computed separately at $1,6,15,24$, and 36 as family income divided by the appropriate poverty threshold (U.S. Government Printing Office, 1993) for each household size and number of children under 18 and averaged across all ages of measurement to produce an index of average income to needs ratio. The income to needs ratio is an index of family economic resources, with higher scores indicating greater financial resources in the household. Maternal education indexed the number of years of schooling that the mother had at the one-month interview.

Five variables reflective of psychosocial risk were included in the cumulative risk index. Maternal depression (collected at all five time points) was assessed using the Center for Epidemiological Studies Depression scale (Radloff, 1977), a self-report measure designed to assess depressive symptomatology in the general population. Cronbach's alpha coefficients ranged from .88 to .91 in our sample. Average maternal depression was based on the average of repeated evaluations of maternal depressive symptomatology. Parenting stress was assessed at all five time points by means of a 30 -item modified, three-subscale version of the 101item Parenting Stress Index (Abidin, 1983). The three subscales were Attachment, Restrictions of Role, and Sense of Competence. Notably, items dealing with child behavior problems were not included. The measure was designed to assess the parent's difficulties coping with the demands of childrearing. Chronbach's alpha indicated high internal consistency at each measurement occasion (>.65). Average parenting stress was based on the average of measurements over time.

Social support was assessed at all five time points and was measured using the 11-item Relationships with Other People questionnaire (Marshall \& Barnett, 1991), in which the respondent rates support over the past month. The measure was designed to assess the individual's general perception of the availability of social support. Cronbach's alphas indicated high internal consistency (over .90) at each time point. Average social support was based on the average of measurements over time.

Average marital quality was assessed us- ing the six-item intimacy subscale of the Personal Assessment of Intimacy in Relationships Inventory (Schaefer \& Olson, 1981), which was completed during the 1- and 36month home interviews with the mother. The subscale scores (based on an average of the six responses; Cronbach's alpha .80 and .86 for 1 and 36 months, respectively) were standardized and summed.

Finally, maternal psychological adjustment, assessed at 6 months only, is a composite variable computed as the mean of three subscales taken from the NEO Personality Inventory (Costa \& McRae, 1985): neuroticism, extraversion, and agreeableness. Neuroticism assesses the extent to which the mother is anxious, hostile, and depressed; extraversion is the extent to which she is sociable, funloving, and optimistic; and agreeableness is the extent to which she is trusting, helpful, and forgiving. Scores on Agreeableness and Extraversion were summed before subtracting Neuroticism to create the composite measure.

Two variables reflective of sociocultural risk were also included in the cumulative contexual-risk index employed in this study: frequency of single-parent status reflected the number of measurement occasions out of five that mothers reported not living with a partner, and minority status was scored whenever a child's race was characterized by mother as any race other than European American.

Given the focus on cumulative risk, we defined risk status separately for each risk variable by specifying a cut-point (see below) and then defined cumulative risk in terms of the number of risk factors that any one case qualified for. For all risk variables except maternal education, minority status, and income, risk status was defined as falling in the least favorable $20 \%$ of the sample (e.g., top $20 \%$ for maternal depression, bottom $20 \%$ for social support). Income risk status was operationalized in terms of an income to needs ratio falling below the poverty threshold (i.e., <1.0). Fewer than 12 years of education defined education risk status. For income and maternal education, respectively, these cut-points assigned risk status to 10.6 and $25.4 \%$ of the sample. Non-European American ethnic status was also considered a risk factor.

Across the sample as a whole, $43.9 \%$ re- 
ceived scores of 0 (out of a maximum of 9) on cumulative risk; $21 \%$ attained risk scores of $1,13.1 \%$ scores of 2 , and a further $22 \%$ attained risk scores of 3 or higher. These four subgroups defined four levels of cumulative risk examined in this report: none, few, moderate, and high. This definition accords well with previous operationalizations of cumulative risk and divides the sample into groups of adequate size to permit analyses with reasonable statistical power. Of those families that fell into the high-risk category, 93 had three risks, 51 had four, 31 had five, 22 had six, 7 had seven, 3 had eight, and 1 had nine. To be noted is that, although for purposes of maintaining statistical power, we report results using only four risk groups (i.e., $0,1,2$, $\leq 3$ ), analyses not presented revealed that further dividing the high-risk group did not appreciably change the results to be reported.

Three-year child development outcomes. Five child-outcome variables were assessed by a variety of measurement strategies. The Bracken Scale of Basic Concepts (Bracken, 1984) consists of the Diagnostic scale and two screening tests and is designed to assess a child's knowledge of basic concepts. Children were tested on the subscales that comprise the school readiness composite of the Diagnostic scale during the home visit at 36 months. This composite consists of five categories and 51 items assessing children's knowledge of color, letter identification, number/counting, comparisons, and shape recognition.

Designed to test verbal comprehension and expressive language skills in young children, the Reynell (1991) Developmental Language scales comprise two 67-item scales and yield two scores, verbal comprehension and expressive language. For the verbal comprehension items, children are presented with sets of objects, and the examiner gives the child instructions such as "Where's the spoon?" or "Put all the white buttons in the cup." To assess expressive language, the examiner observes the structure of the child's speech (e.g., child has one or more appropriate uses of past tense, child uses complex sentences) and asks the child to label objects, describe objects or activities observed in a picture, and define words. The internal consistency for this test is very high with alphas in excess of .85 for each of the two subscales.

Maternal-report questionnaires were used to generate composite measures of behavior problems and social competence. The 99-item Child Behavior Checklist-2/3 (CBCL; Achenbach, Edelbrock, \& Howell, 1987) was used to assess problem behavior. Mothers rated how characteristic each behavior was of their child over the last 2 months $(0=$ not true, $1=$ sometimes true, $2=$ very true). We analyze the total score. Research indicates that the CBCL-2/3 shows good test-retest reliability and concurrent and predictive validity; it discriminates between clinically referred and nonreferred toddlers and predicts problem scores over a 3-year period (Achenbach et al., 1987).

Social competence and disruptive behavior were assessed with the Adaptive Social Behavior Inventory (ASBI; Hogan, Scott, \& Bauer, 1992). This measure was originally standardized on a sample of 545 geographically and ethnically diverse toddlers. The 30 items were rated in terms of frequency of occurrence $(1=$ rarely, 2 = sometimes, 3 = almost always). Factor analysis on the original sample yielded three interpretable factors (Express, Comply, Disrupt) with good internal consistency and concurrent validity (Hogan et al., 1992). The Express scale (13 items) taps sociability and empathy, and the Comply scale (10 items) measures prosocial engagement and social competence. The Disrupt scale (7 items) assesses resistant and agonistic behavior. In the NICHD sample the coefficient alphas for these scales were .76 for Express, .82 for Comply, and .62 for Disrupt.

When the aforementioned subscales from the CBCL and ASBI were factored for a previous report examining effects of early child care on child functioning (NICHD Early Child Care Research Network, 1998), two clear factors emerged reflecting mother-reported problem behavior and social competence. As in that previous work, high loading variables (>.65) were combined to create two scores. The problem behavior composite included all four of the CBCL scales and the ASBI disrupt scale. The social competence composite included the Express and Comply subscales from the ASBI. 
Table 2. Mean 36-month child outcome scores (standard deviations) as a function of 15-month attachment

\begin{tabular}{|c|c|c|c|c|c|c|c|}
\hline \multirow[b]{3}{*}{ Outcome Variable } & \multicolumn{4}{|c|}{ Attachment Classifications } & \multirow{2}{*}{\multicolumn{3}{|c|}{ Sample Statistics }} \\
\hline & \multirow{2}{*}{$\begin{array}{c}\text { A } \\
(n=118)\end{array}$} & \multirow{2}{*}{$\begin{array}{c}\mathrm{B} \\
(n=593)\end{array}$} & \multirow{2}{*}{$\begin{array}{c}\mathrm{C} \\
(n=88)\end{array}$} & \multirow{2}{*}{$\begin{array}{c}\mathrm{D} \\
(n=147)\end{array}$} & & & \\
\hline & & & & & $F$ & $p$ & $\varepsilon^{2}$ \\
\hline Behavior problems & $\begin{array}{l}113.81 \\
(17.22)\end{array}$ & $\begin{array}{c}111.91 \\
(17.59)\end{array}$ & $\begin{array}{l}114.95 \\
(15.63)\end{array}$ & $\begin{array}{l}110.38 \\
(18.72)\end{array}$ & 1.63 & .181 & .006 \\
\hline Social competence & $\begin{array}{c}57.04 \\
(5.39)\end{array}$ & $\begin{array}{c}58.64 \\
(5.16)\end{array}$ & $\begin{array}{c}57.91 \\
(5.63)\end{array}$ & $\begin{array}{l}59.30 \\
(5.07)\end{array}$ & 4.74 & .003 & .016 \\
\hline Language comprehension & $\begin{array}{l}34.80 \\
(6.34)\end{array}$ & $\begin{array}{l}37.65 \\
(6.68)\end{array}$ & $\begin{array}{l}36.99 \\
(7.42)\end{array}$ & $\begin{array}{l}36.65 \\
(7.22)\end{array}$ & 6.03 & .0004 & .019 \\
\hline Expressive language & $\begin{array}{l}34.36 \\
(6.49)\end{array}$ & $\begin{array}{l}36.05 \\
(6.17)\end{array}$ & $\begin{array}{l}36.19 \\
(6.95)\end{array}$ & $\begin{array}{l}36.52 \\
(6.36)\end{array}$ & 3.00 & .031 & .010 \\
\hline School readiness & $\begin{array}{c}39.07 \\
(25.74)\end{array}$ & $\begin{array}{c}44.79 \\
(26.13)\end{array}$ & $\begin{array}{c}42.71 \\
(26.89)\end{array}$ & $\begin{array}{c}39.94 \\
(25.76)\end{array}$ & 2.49 & .059 & .008 \\
\hline
\end{tabular}

\section{Results}

Results are presented in four sections. First, to afford comparison with results of other studies, direct, unadjusted, and unmoderated effects of attachment security at 15 months on socioemotional and cognitive-linguistic functioning at 3 years are presented. Second, linear and nonlinear relations between risk and 36-month developmental outcomes are examined. In the third section, relations between contextual risk and attachment are presented. The final stage of analysis focuses on the interaction of early attachment and cumulative risk in predicting child functioning at age 3 years.

\section{Attachment and socioemotional and cognitive outcomes}

To assess effects of mother-infant attachment security on developmental outcome at 36 months irrespective of social-contextual risk, we carried out a series of one-way analyses of variance, testing for univariate associations between attachment group and outcome. Inspection of Table 2 reveals that for three of five dependent variables, significant differences across attachment groups were found. Visual inspection of means indicate in all cases where significant differences were evident that infants classified as avoidant evinced the least social competence and expressive and receptive language of all four attachment groups. Notably, the sizes of all attachment effects were modest, accounting for less than $2 \%$ of the variance in the outcomes when significant.

Post hoc Sidak comparisons of pairwise differences in means broadly confirmed the picture of results just provided. Avoidant infants scored significantly lower, on average, than secure $(p<.01)$ and disorganized $(p<$ $.01)$ infants. For language comprehension, the avoidant group scored significantly lower than the secure group $(p<.0001)$. Avoidant infants also scored significantly lower on expressive language than both the secure $(p<$ $.05)$ and disorganized infants $(p<.05)$. No other group difference was significant.

In sum, rather than poor outcome being associated with attachment insecurity in general, results indicate that some poor outcomes are more specifically associated with insecure-avoidant attachment. Notably, there was little evidence from these data that infants classified as disorganized were at any special risk for poor socioemotional or cognitivelinguistic outcome at age 3 years. This could have something to do with the loss over time in this study of some of the most at-risk families (see Discussion).

\section{Cumulative risk and developmental outcomes}

The magnitude and form of relations between cumulative risk and each developmental out- 
Table 3. Mean 36-month child outcome scores (standard deviations) as a function of cumulative contextual risk $(N=946)$

\begin{tabular}{|c|c|c|c|c|c|c|c|c|}
\hline \multirow[b]{2}{*}{ Outcome } & \multicolumn{4}{|c|}{ Cumulative Risk } & \multirow[b]{2}{*}{$\varepsilon^{2}$} & \multicolumn{3}{|c|}{$\begin{array}{c}\text { Polynomial Contrasts } \\
p \text { Values }\end{array}$} \\
\hline & $\begin{array}{l}\text { None } \\
(0)\end{array}$ & $\begin{array}{l}\text { Few } \\
(1)\end{array}$ & $\begin{array}{l}\text { Moderate } \\
\text { (2) }\end{array}$ & $\begin{array}{c}\text { High } \\
(3+)\end{array}$ & & Linear & Quadratic & Cubic \\
\hline Behavior problems & $\begin{array}{l}106.61 \\
(15.14)\end{array}$ & $\begin{array}{l}111.05 \\
(15.96)\end{array}$ & $\begin{array}{l}115.85 \\
(18.39)\end{array}$ & $\begin{array}{l}122.24 \\
(18.25)\end{array}$ & .124 & $<.001$ & .408 & .836 \\
\hline Social competence & $\begin{array}{l}60.00 \\
(4.74)\end{array}$ & $\begin{array}{l}58.83 \\
(4.97)\end{array}$ & $\begin{array}{l}57.20 \\
(5.44)\end{array}$ & $\begin{array}{l}55.89 \\
(5.24)\end{array}$ & .100 & $<.001$ & .825 & .648 \\
\hline Language comprehension & $\begin{array}{l}38.90 \\
(6.68)\end{array}$ & $\begin{array}{l}36.67 \\
(5.96)\end{array}$ & $\begin{array}{l}35.90 \\
(6.65)\end{array}$ & $\begin{array}{l}34.54 \\
(7.09)\end{array}$ & .066 & $<.001$ & .355 & .384 \\
\hline Expressive language & $\begin{array}{l}37.08 \\
(6.08)\end{array}$ & $\begin{array}{l}35.82 \\
(5.90)\end{array}$ & $\begin{array}{l}35.57 \\
(7.05)\end{array}$ & $\begin{array}{l}33.94 \\
(6.31)\end{array}$ & .037 & $<.001$ & 677 & .275 \\
\hline School readiness & $\begin{array}{l}48.72 \\
(24.07)\end{array}$ & $\begin{array}{l}43.36 \\
(25.50)\end{array}$ & $\begin{array}{c}41.41 \\
(28.12)\end{array}$ & $\begin{array}{l}32.77 \\
(26.48)\end{array}$ & .055 & $<.001$ & .367 & .261 \\
\hline
\end{tabular}

Table 4. Distribution of attachment classifications by cumulative contextual risk

\begin{tabular}{lrrrr}
\hline \hline & \multicolumn{4}{c}{ Cumulative Risk Frequency (\%) } \\
\cline { 2 - 5 } Attachment & \multicolumn{1}{c}{$\begin{array}{c}\text { None } \\
(0)\end{array}$} & \multicolumn{1}{c}{ Low } & \multicolumn{1}{c}{ Moderate } & \multicolumn{1}{c}{$\begin{array}{c}\text { High } \\
(1)\end{array}$} \\
\hline Avoidant & $48(11.6)$ & $25(12.6)$ & $21(16.9)$ & $24(11.5)$ \\
Secure & $278(67.0)$ & $116(58.3)$ & $73(58.9)$ & $126(60.6)$ \\
Resistant & $38(9.2)$ & $20(10.1)$ & $9(7.3)$ & $21(10.1)$ \\
Disorganized & $51(12.3)$ & $38(19.1)$ & $21(16.9)$ & $37(17.8)$ \\
\hline \hline
\end{tabular}

come were assessed in a series of GLM oneway analyses of variance. Orthogonal polynomial contrasts tested linear and nonlinear components of the effects of risk on outcome. With four levels of the cumulative risk variable, polynomials of degree 1 (linear), 2 (quadratic), and 3 (cubic) were tested. Highly significant differences between the four cumulative risk groups on all developmental outcomes emerged (see Table 3) and significant linear effects revealed that as cumulative risk increased, developmental functioning decreased. Cumulative risk accounted for a somewhat greater proportion of the variance in socioemotional than cognitive-linguistic outcomes.

\section{Association between attachment and risk}

Given that this study is concerned with the possibility that attachment and risk interact in predicting later development, it is important to consider the extent to which attachment and risk are themselves associated. Furthermore, as discussed in the introduction to this paper, in the absence of Attachment $\times$ Risk interactions, it is important to consider the possibility that attachment main effects arise primarily as an artifact of associations between attachment and risk. Table 4 shows the distribution of attachment classifications across the four levels of cumulative risk. There was no significant association between these measurements $\chi^{2}(9)=10.8, p=.29$.

\section{Attachment $\times$ Risk interactions}

Interaction effects of attachment and cumulative risk on developmental outcomes were assessed in a series of hierarchical multiple regression analyses, one for each outcome measure. The four attachment groups were 
Table 5. Results of hierarchical regression analyses of risk, attachment, and 36-month outcomes $(N=946)$

\begin{tabular}{|c|c|c|c|c|c|c|c|c|}
\hline \multirow[b]{3}{*}{ Outcome } & \multirow{2}{*}{\multicolumn{2}{|c|}{ Main Effects ${ }^{a, b}$}} & \multicolumn{6}{|c|}{ Attachment $\times$ Risk and Interactions } \\
\hline & & & \multirow{2}{*}{ 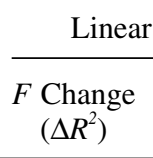 } & \multirow[b]{2}{*}{$p$} & \multicolumn{2}{|c|}{ Quadratic } & \multicolumn{2}{|c|}{ Cubic } \\
\hline & $\begin{array}{l}\text { Attachment } p \\
\left(\Delta R^{2}\right)\end{array}$ & $\begin{array}{c}\text { Risk } p \\
\left(\Delta R^{2}\right)\end{array}$ & & & $\begin{array}{c}F \text { Change } \\
\left(\Delta R^{2}\right)\end{array}$ & $p$ & $\begin{array}{c}F \text { Change } \\
\left(\Delta R^{2}\right)\end{array}$ & $p$ \\
\hline Behavior problems & $\begin{array}{l}.074 \\
(.006)\end{array}$ & $\begin{array}{c}<.0001 \\
(.124)\end{array}$ & $\begin{array}{c}0.984 \\
(0.003)\end{array}$ & .399 & $\begin{array}{c}0.444 \\
(0.001)\end{array}$ & .718 & $\begin{array}{c}4.982 \\
(0.014)\end{array}$ & .002 \\
\hline Social competence & $\begin{array}{l}<.001 \\
(.016)\end{array}$ & $\begin{array}{c}<.0001 \\
(.100)\end{array}$ & $\begin{array}{c}3.079 \\
(0.009)\end{array}$ & .027 & $\begin{array}{c}0.866 \\
(0.002)\end{array}$ & .458 & $\begin{array}{c}3.237 \\
(0.009)\end{array}$ & .022 \\
\hline Language comprehension & $\begin{array}{l}<.001 \\
(.016)\end{array}$ & $\begin{array}{c}<.0001 \\
(.063)\end{array}$ & $\begin{array}{c}1.154 \\
(0.003)\end{array}$ & .326 & $\begin{array}{c}0.501 \\
(0.001)\end{array}$ & .681 & $\begin{array}{c}0.158 \\
(<0.001)\end{array}$ & .924 \\
\hline Expressive language & $\begin{array}{l}.020 \\
(.010)\end{array}$ & $\begin{array}{c}<.0001 \\
(.037)\end{array}$ & $\begin{array}{c}5.764 \\
(0.017)\end{array}$ & .001 & $\begin{array}{c}2.133 \\
(0.006)\end{array}$ & .094 & $\begin{array}{c}0.662 \\
(0.002)\end{array}$ & .575 \\
\hline School readiness & $\begin{array}{l}.114 \\
(.006)\end{array}$ & $\begin{array}{l}<.0001 \\
(.053)\end{array}$ & $\begin{array}{c}0.799 \\
(0.002)\end{array}$ & .495 & $\begin{array}{c}0.208 \\
(0.001)\end{array}$ & .891 & $\begin{array}{c}0.127 \\
(<0.001)\end{array}$ & .944 \\
\hline
\end{tabular}

${ }^{a} F$ statistics are not shown for main effects due to limitations of space.

${ }^{b}$ Note that because model testing is sequential, the $p$ values for main effects refer to effects of attachment and risk, controlling only for both main effects, not for higher order interaction terms. Where higher order terms are significant, these $p$ values may not be meaningful.

coded as dummy variables, according to standard procedures (e.g., see Darlington, 1968), with the secure group defined as the reference category; this yielded three dummy variables: $A$ versus not- $A, C$ versus not- $C$, and $D$ versus not-D. Risk was polynomial contrast-coded, with codes representing the linear, quadratic, and cubic components of risk, according to standard orthogonal polynomial contrast procedures. Interactions were specified as multiplicative terms between the attachment dummy variables and the risk polynomial contrast variables, again following standard procedures (Darlington, 1968). Hypothesis testing proceeded hierarchically: attachment and risk main effects were entered first, followed in three subsequent steps by the Attachment $\times$ Linear Risk interaction terms, the Attachment $\times$ Quadratic Risk interaction terms, and the Attachment $\times$ Cubic Risk interaction terms. The overall significance of Attachment $\times$ Risk interactions was tested by the $F$ statistic associated with the change in $R^{2}\left(\Delta R^{2}\right.$ in Table 5) from one step to the next.

Because of the hierarchical nature of these analyses, the significance values of lower order terms presented in Table 5 are assessed without controlling for higher order ones. Sequential model testing is used to select the best-fitting model. For example, if adding a quadratic interaction term leads to a significant increase in fit over a linear model (main effects plus linear interaction), but adding the cubic term does not result in an improvement in model fit (i.e., the $F$ change is not significant), the best fitting model is presumed to be the one that includes only main effects, linear interactions, and quadratic interactions. In instances where no interactions lead to an improvement in model fit, a main effects model is chosen as the best fit. This is particularly important when interpreting the $p$ values associated with the main effects of attachment and risk, which will only reflect the appropriate significance of the main effects in the best-fitting model if no interaction terms are significant.

The results of sequential model testing for each outcome are displayed in Table 5. (No significant gender interactions were found when these analyses were run with gender in the model.) The first thing to note is that, in the case of school readiness and language comprehension, main effects models appeared to be the best fit; that is, no significant interactions between attachment and risk were detected. The main effects presented in the table represent effects of attachment controlling for risk (and vice versa). As in the earlier analysis 
Table 6. Polynomial regression coefficients for risk outcome analyses estimated separately for each attachment group

\begin{tabular}{|c|c|c|c|c|c|}
\hline \multirow[b]{2}{*}{ Outcome } & \multicolumn{5}{|c|}{ Standardized Risk Outcome Regression Coefficients } \\
\hline & A & B & $\mathrm{C}$ & $\mathrm{D}$ & $\begin{array}{l}\text { Significant } \\
\text { Differences }\end{array}$ \\
\hline \multicolumn{6}{|c|}{ Behavior problems } \\
\hline Linear & $.488 * * *$ & $.303 * * *$ & $.377 * * *$ & $.401 * * *$ & - \\
\hline Quadratic & .021 & .007 & .141 & .066 & - \\
\hline Cubic & $-.299 * * *$ & .062 & .147 & .016 & $\mathrm{~A}<\mathrm{B}, \mathrm{C}, \mathrm{D}$ \\
\hline \multicolumn{6}{|c|}{ Social competence } \\
\hline Linear & $-.484 * * *$ & $-.274 * * *$ & $-.469 * * *$ & $-.249 * *$ & $\begin{array}{l}\mathrm{A}<\mathrm{B}, \mathrm{D} \\
\mathrm{C}<\mathrm{B}, \mathrm{D}\end{array}$ \\
\hline Quadratic & .032 & -.014 & -.185 & .052 & - \\
\hline Cubic & $.236 * *$ & -.039 & -.109 & .041 & $\mathrm{~A}>\mathrm{B}, \mathrm{C}$ \\
\hline \multicolumn{6}{|c|}{ Expressive language } \\
\hline Linear & $-.339 * * *$ & -.072 & $-.423 * * *$ & $-.311 * * *$ & $\mathrm{~B}>\mathrm{A}, \mathrm{C}, \mathrm{D}$ \\
\hline Quadratic & -.044 & .030 & $-.215^{*}$ & -.030 & $\mathrm{~B}>\mathrm{C}^{a}$ \\
\hline Cubic & .055 & -.078 & -.036 & -.022 & - \\
\hline
\end{tabular}

Note: Coefficients with no asterisk are not significant at $p<.05$.

${ }^{a}$ Although this difference was significant in pairwise comparisons, the overall test of Attachment $\times$ Quadratic Risk was not significant. Hence, this difference should be treated with caution.

$* p<.05 . * * p<.005 . * * * p<.001$.

(see Table 2), there is no main effect of attachment on school readiness, but there is a main effect of attachment-this time after controlling for contextual risk-on expressive language. Thus, a simple third-variable explanation does not account for the earlier discerned effect of attachment on language comprehension. Furthermore, the effect size for language comprehension $\left(\varepsilon^{2}\right.$ in Table 2$)$ was not appreciably changed after controlling for risk $\left(\Delta R^{2}\right.$ in Table 5). The values of $\Delta R^{2}$ for the main effects in Table 5 were determined by the change in $R^{2}$ when the main effect in question was added to a regression model that already included the other main effect.

The results of the best-fitting model analyses displayed in Table 5 indicate that Attachment $\times$ Risk interactions achieved conventional levels of statistical significance in the case of three outcomes: behavior problems, social competence, and expressive language. In the case of behavior problems, the Attachment $\times$ Risk interaction resulted from differences between attachment groups in the cubic component of the risk-outcome relationship. In other words, there was variability between the attachment groups in aspects of the curvilinear relationship between risk and outcome, and particularly the extent to which the relationship is characterized by turning points. The best-fitting model for behavior problems is thus one in which all main effects and interactions are included. For social competence, there were significant differences in both linear and cubic terms, reflecting differences in overall slope and curvature, again indicating that the full model with all main effects and interactions is the best-fitting model. Finally, for expressive language, the risk-attachment interaction involved only a linear component of risk, indicating differences between the attachment groups in the (linear) strength of association between risk and expressive language development. The best-fitting model for expressive language is thus one in which main effects and Attachment $\times$ Linear Risk terms are included.

In order to explore further these attachment-risk interactions, we carried out a series of post hoc pairwise tests of group differences in polynomial regression coefficients in those instances where overall between-group differences were evident in Table 5. The polynomial regression coefficients for the four attachment groups, estimated separately for each group, are also shown in Table 6 for the 


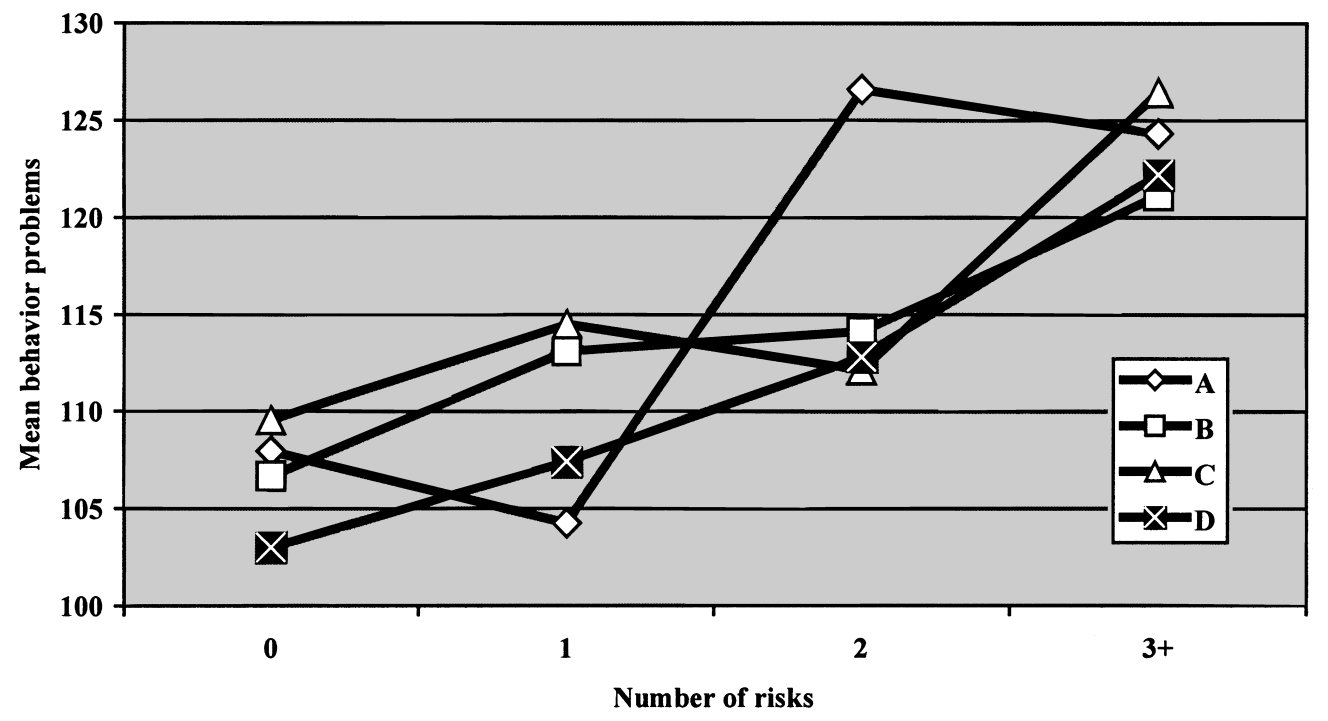

Figure 1. Mean behavior problems score as a function of attachment and cumulative risk.

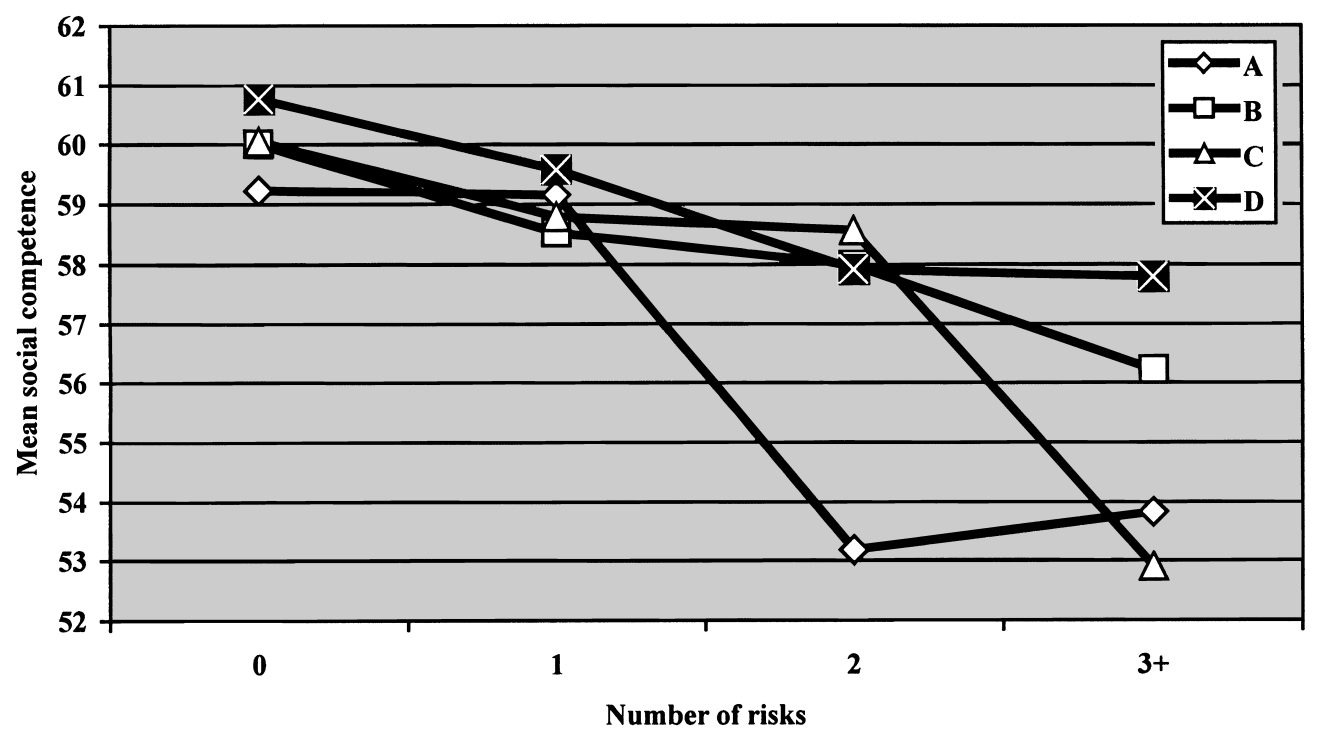

Figure 2. Mean social competence score as a function of attachment and cumulative risk.

purposes of illustration, and plots of estimated means for each attachment group at each level of risk are shown in Figures 1-3. We now discuss each of the three outcome domains in turn.

Behavior problems. Examination of Figure 1 facilitates interpretation of differences in the risk-outcome associations shown in Table 6, indicating a strong stepup in behavior problems for the avoidant group at risk level 2, attaining levels of behavior problems that the other attachment groups reach only at higher levels of contextual risk (i.e., 3+). It is this large increase at risk level 2 , coupled with a small decrease between risk levels 0 and 1 that gives rise to the significant cubic term for the avoidant group. Simple effects of attach- 


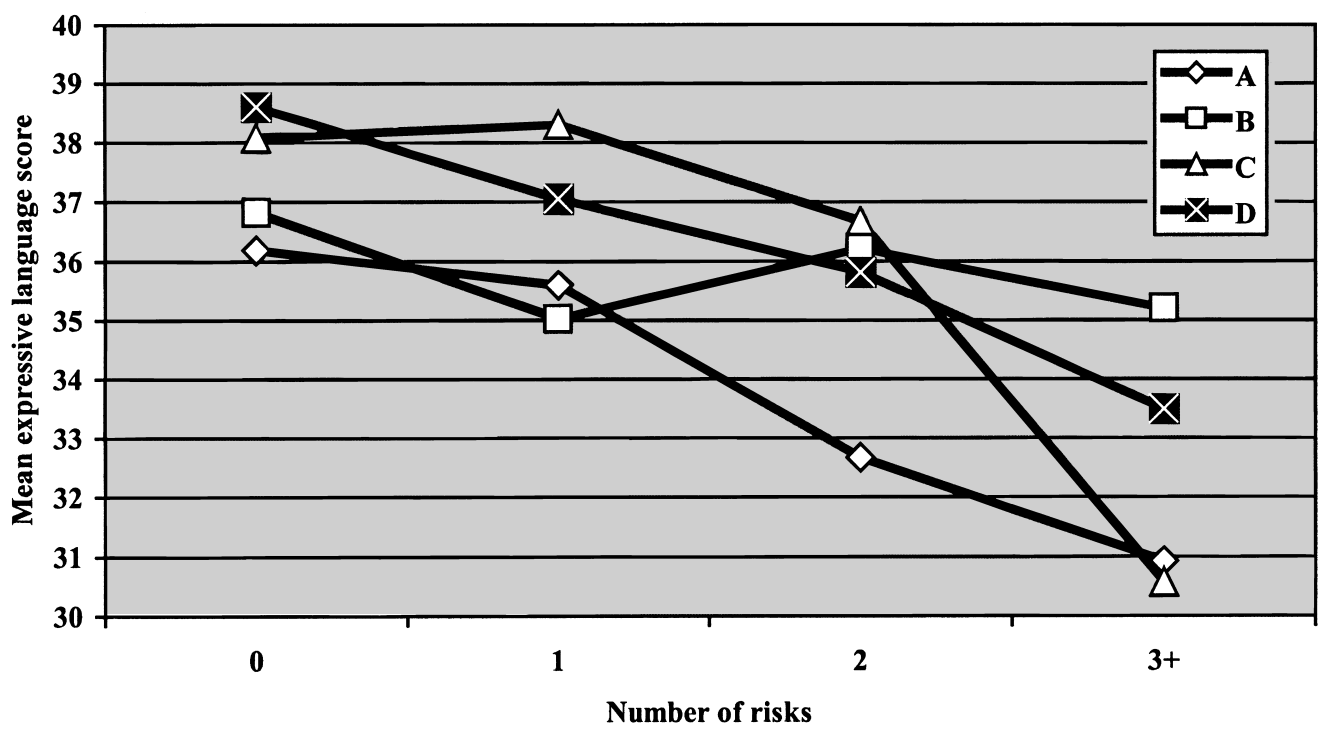

Figure 3. Mean expressive language score as a function of attachment and cumulative risk.

ment at each level of risk indicated significant differences between the means of attachment groups at risk levels 1 and $2, F(3,930)=$ $2.993, p=.030$, and $F(3,930)=3.681, p=$ .012 , respectively, but not when no risks were present nor when three or more risks were present. Sidak post hoc comparisons of group means at risk level 1 revealed no pairwise differences between attachment groups at risk level 1, however. At risk level 2 the avoidant group had significantly higher levels of mean behavior problems than the secure $(p=.013)$ and disorganized $(p=.039)$ groups. At this level of risk, attachment accounted for approximately $7.1 \%$ of the variance in behavior problems.

Social competence. Inspection of Figure 2 reveals an interesting picture that seems consistent with the heightened-vulnerability perspective in the case of insecure-avoidant and insecure-resistant attachments described earlier. First, the avoidant and resistant groups show a decrease in social competence associated with contextual risk to a greater extent than the secure and disorganized attachment groups. (Consistent with this, the linear terms for these groups were more negative.) Second, although the resistant group appears vulnerable to high levels of contextual risk, this vul- nerability seems to emerge at a higher level of risk than is the case for the avoidant group. Thus, whereas children with insecure-avoidant and insecure-resistant attachments seemed particularly susceptible to the adverse effects of contextual risk on social competence, children with histories of avoidant attachment succumbed to this risk at lower levels of risk than children with resistant attachment histories. The "step-function" appearance of the risk curve for avoidant infants (with an abrupt decrease in social competence at risk level 2 and a subsequent plateau) would seem to be responsible for the significant cubic term in this group (see Tables 5 and 6).

To some extent, this interpretation is supported by simple effects analysis and post hoc comparisons. Simple effects of attachment at each level of risk revealed significant differences between the attachment groups in social competence at risk level 2 and at the high-risk (i.e., 3+) level, $F(3,930)=5.616, p<.001$, and $F(3,930)=6.013, p<.001$, respectively. At risk level 2 Sidak post hoc comparisons indicated that the avoidant group scored lower on average on social competence than the secure, resistant and disorganized groups $(p<$ $.001, p=.038$, and $p=.012$, respectively). At this level of risk, attachment accounted for $11.2 \%$ for the variance in social competence. 
At the high level of risk, the avoidant group was significantly different from the disorganized group ( $p=.013)$. Indeed, the disorganized group also evinced significantly greater social competence than the resistant group ( $p=$ $.002)$. The difference between the secure and the disorganized group was not, however, significant, although notably, neither was the difference between the secure and avoidant groups. On the other hand, the difference between the secure and the resistant groups was significant $(p=.026)$. At risk level 3 attachment accounted for approximately $7.7 \%$ of the variance in social competence.

Expressive language. Examination of Figure 3 reveals that the secure group, in contrast to the other attachment categories, did not show decreases in expressive language skills with increasing social risk. Consistent with this, Table 6 shows that the linear term for the secure group was significantly less negative than the other attachment groups (and indeed, the linear term for the secure group was not significantly different from zero). Simple effects of attachment at each level of risk revealed differences between attachment groups only at the level of high contextual risk, $F$ (3, $930)=5.877, p<.001$. Sidak post hoc comparisons indicated that the secure group scored higher in terms of expressive language skills than both the avoidant $(p=.011)$ and resistant groups $(p=.009)$ but not the disorganized group $(p=.582)$ at this high level of risk. No other group difference was significant. At this high level of risk, attachment accounted for approximately $8.1 \%$ of the variance in expressive language skills.

\section{Discussion}

The primary purpose of the present paper was to assess effects of attachment (at 15 months) on socioemotional, cognitive, and linguistic development (at 36 months), directly and in relation to cumulative contextual risk. The data archive from the first 3 years of the NICHD Study of Early Child Care afforded an ideal opportunity to address this issue. Not only does it provide large subsample sizes across varying levels of social-contextual risk, but it also includes, in consequence, reason- able numbers of children with insecure attachments (i.e., A, C, D). The sample is not without its limits, however, especially when issues of differential attrition are considered (see below).

The findings of our analyses, based on 946 mother-infant dyads, were consistent with the view that (a) individual differences in patterns of attachment in infancy are associated with later socioemotional and language development in early childhood, (b) but not more general cognitive ability, as indexed by a measure of school readiness, and (c) that the effects of attachment on at least some outcome domains vary as a function of cumulative contextual risk. With regard to the first two points, attachment security was found to exert a direct, unmoderated effect on language comprehension but not school readiness, thus replicating the meta-analytic results of van Ijzendoorn et al. (1995). Extending those findings, results of the research reported herein indicate that the main effect of attachment on language functioning could not be accounted for by contextual risk, although the possibility remains that some unmeasured third variables are responsible.

Although direct effects of attachment were also observed for social competence and expressive language, both of these findings were qualified by significant Risk $\times$ Attachment interactions. Relatedly, the effect of attachment security on problem behavior was only evident when contextual risk was considered. In the case of all moderated effects, attachment security appeared to operate in accord with risk resilience mechanisms, in that its predictive power varied as a function of socialcontextual risk, with attachment predicting socioemotional development and expressive language skills only, or primarily, under conditions of social contextual risk. The problem behavior results are generally consistent with findings from several prior investigations in which attachment security was found to predict behavior problems better among children growing up in higher risk environments (Erickson et al., 1985; Munson et al., 2001; Shaw \& Vondra, 1995), but not among children growing up in low-risk environments (Bates et al., 1985; Belsky et al., 1998). What is new and perhaps especially noteworthy, 
however, is that the nature of the risk-resilience process appeared different for different outcomes.

In the case of expressive language development, the findings of the current study were consistent with what might be regarded as a simple risk-resilience model of attachment and later development in which security functions as a protective factor. Recall that whereas the expressive language abilities of children with insecure attachment histories declined as contextual risk increased, this was not the case for children with secure attachment histories. Security, therefore, appeared to play a clear protective function when it came to children's ability to use spoken language.

For both socioemotional outcomes, the nature of the risk-resilience process was rather different. In the case of problem behavior and social competence, it was the avoidant group that appeared to be most differentially affected by contextual risk, evincing adverse effects of cumulative contextual risk at a level of risk lower than that at which all other attachment groups "succumbed" to contextual risk. In the case of behavior problems, whereas the four attachment groups did not differ from each other at low levels of contextual risk (i.e., <1) and all groups were adversely affected by high levels of risk (i.e., 3+), at moderate levels of risk (i.e., 2) children with insecure-avoidant attachment histories showed the same level of poor functioning that the three other attachment groups evinced only at high levels of risk. A similar pattern emerged for social competence, with the avoidant group showing a marked decrease in performance under conditions of risk level 2. In a sense, then, the avoidant group proved more vulnerable to contextual risk - at least at a lower level of risk - than children in all other groups. When levels of risk became especially high, however, even a history of attachment security failed to protect children from the adverse effects of growing up in a developmentally adverse environment.

Results of this investigation are consistent with the view that infant-mother attachment security, either in conjunction with risk or by itself, is a reliable predictor of later development. Not to be forgotten, however, is that the degree of prediction is limited, accounting for consistently less variance in developmental outcomes than contextual risk. Apparently, knowing the ecological conditions under which a young child develops is more informative with respect to that child's development than knowledge of the security of the infant-mother attachment relationship, although knowing about both is often more informative than knowing about just one. Not to be ignored, however, is the possibility that the predictive power of contextual risk relative to that of attachment may have been heightened by the fact that many of the outcomes of this study, like the indices of contextual risk themselves, were based on maternal reports.

The results of this investigation point to some important considerations regarding the specificity of risk associated with different patterns of attachment. In the socioemotional domain, our results seem to indicate that it is not so much that attachment security is associated with better outcomes or is protective against contextual risk, but rather that insecure-avoidant attachment is associated with poorer outcomes, particularly at moderate levels of contextual risk. With respect to language comprehension, children with insecure-avoidant attachment histories performed most poorly, irrespective of level of contextual risk. Notably, for social competence and expressive language skills, resistant infants also showed greater deficits, but only at the highest level of risk. Importantly, infants classified as disorganized appeared to be at no greater risk for poorer functioning at age 3 years than agemates with secure attachment histories. It seems appropriate to conclude, therefore, at least with respect to the domains of development considered in this report, that it is insecure-avoidant attachment, and perhaps insecure-resistance, that should be considered with risk or most susceptible to contextual risk, rather than a broad developmental advantage associated with attachment security per se or disadvantage associated with attachment insecurity in general.

In certain respects such a conclusion is consistent with other evidence in the literature. Not only is it the case that in most studies of the sequelae of attachment, especially before the emergence of $\mathrm{D}$ coding, most cases 
classified insecure were of the avoidant variety (van Ijzendoorn, Goldberg, Kroonenberg, \& Frenkel, 1992; van Ijzendoorn \& Kroonenberg, 1988), but other research dealing with behavior problems documents associations between early insecure-avoidance and problem behavior, albeit sometimes in interaction with other factors and not across all problem domains (Erickson et al., 1985; Fagot \& Kavanagh, 1990; Lewis, Feiring, McGuffog, \& Jaskir, 1984; Munson et al., 2001; Renken et al., 1989; Troy \& Sroufe, 1987). For example, Goldberg, Gotowiec, and Simmons (1995) found, in a mixed sample of children with and without significant health problems, that only the avoidant group evinced higher levels of internalizing and externalizing behavior problems at age 4 years. As in the current investigation, there were no differences in behavior problems among the secure, ambivalent, and disorganized groups.

Despite some consistency between the results of this inquiry and several others, it must be acknowledged that the finding that disorganization was not obviously a risk factor for poor socioemotional and cognitive-linguistic outcomes is surprising in the context of accumulating evidence of heightened risk for problematic outcomes associated with this attachment history (Carlson, 1998; Greenberg, 1999; Lyons-Ruth, Alpern, \& Repacholi, 1993; Lyons-Ruth \& Jacobvitz, 1999; Shaw, Owens, Vondra, Keenan, \& Winslow, 1996). Reflection on the discrepancy between the results of the current investigation and those of others draws attention to the especial high-risk status of children and families in many of the investigations chronicling particular risks for children with histories of disorganized attachment. Especially when considered in light of the nonrandom attrition that characterized the sample being followed longitudinally as part of the NICHD Study of Early Child Care, it seems conceivable that if more high-risk families with disorganized children remained in the study, the results of this investigation may have been more in line with other research. This limitation of the NICHD Study data set calls for caution when considering the null findings regarding developmental risks associated with disorganized attachment. Moreover, it remains possible that associations between disorganized attachment in infancy and poor functioning later on may yet emerge in the available sample as children develop. Not inconsistent with this prospect is the fact that the majority of outcome studies on infant disorganization have focused on children older than 3 years of age.

Although the current inquiry provides support for the general proposition that the links between attachment security and later socioemotional outcome should be conceptualized in risk-resilience terms, there is still much scope for greater understanding of the specific manner in which social-contextual risk and attachment security interact. It is likely that a greater degree of specificity with respect to putative causal mechanisms will also point to reasons why links between attachment security and, for example, language comprehension are not conditional on contextual risk. Whatever the specific mechanisms turn out to be, increased attention to proximal processes is called for if we are to understand the developmental events that lead to maladaptation and disorder. Furthermore, a better understanding of the specific psychological and social mechanisms by which individual differences in attachment in infancy are translated into difficulties in socioemotional development and language skills in later childhood may also shed further light on the reasons why, in some instances and under some circumstances, otherwise anticipated associations do not emerge.

\section{References}

Abidin, R. (1983). Parenting stress index manual. Charlottesville, VA: Pediatric Psychology Press.

Achenbach, T. M., Edelbrock, C., \& Howell, C. T. (1987). Empirically based assessment of behavioral/ emotional problems of 2- and 3-year-old children. Journal of Abnormal Child Psychology, 15, 629-650.
Ainsworth, M., \& Wittig, B. (1969). Attachment and exploratory behavior of one-year olds in a strange situation. In B. M. Foss (Ed.), Determinants of infant behavior (Vol. 4). London: Methuen.

Bates, J., Maslin, C., \& Frankel, K. (1985). Attachment security, mother-child interaction, and temperament 
as predictors of behavior-problem ratings at age 3 years. In I. Bretherton \& E. Waters (Eds.), Growing points of attachment theory and research. Monographs of the Society for Research in Child Development, 50(1-2, Serial No. 209, pp. 167-193).

Belsky, J. (1996). Parent, infant and social-contextual antecedents of father-son attachment security. Developmental Psychology, 32, 905-914.

Belsky, J., \& Cassidy, J. (1994). Attachment: Theory and evidence. In M. Rutter \& D. Hay (Eds.), Development through life: A handbook for clinicians (pp. 373402). Oxford: Blackwell.

Belsky, J., Fish, M., \& Isabella, R. (1991). Continuity and discontinuity in infant negative and positive emotionality: Family antecedents and attachment consequences. Developmental Psychology, 27, 421-431.

Belsky, J., Hsieh, K., \& Crnic, K. (1998). Mothering, fathering, and infant negativity as antecedents of boys' externalizing problems and inhibition at age 3: Differential susceptibility to rearing influence? Development and Psychopathology, 10, 301-319.

Belsky, J., \& Nezworski, T. (Eds.). (1988). Clinical implications of attachment. Hillsdale, NJ: Erlbaum.

Belsky, J., \& Isabella, R. (1988). Maternal, infant, and social-contextual determinants of infant-mother attachment. In J. Belsky \& T. Nezworski (Eds.), Clinical implications of attachment (pp. 41-94). Hillsdale, NJ: Erlbaum.

Belsky, J., Rosenberger, K., \& Crnic, K. (1995). Maternal personality, marital quality, social support and infant temperament: Their significance for infant-mother attachment in human families. In C. Pryce, R. Martin, \& D. Skuse (Eds.), Motherhood in human and nonhuman primates: A synthetic approach (pp. 115124). Basel, Switzerland: Karger.

Bracken, B. A. (1984). Bracken Basic Concept Scale. San Antonio, TX: Psychological Corporation.

Brooks-Gunn, J., Klebanov, P., Liaw, F., \& Duncan, G. (1995). Toward an understanding of the effects of poverty upon children. In H. E. Fitzgerald, B. Lester, \& B. Zuckerman (Eds.), Children of poverty (pp. 3-37). New York: Garland.

Carlson, E. (1998). A prospective longitudinal study of attachment disorganization/disorientation. Child Development, 69, 1107-1128.

Colin, V. (1996). Human attachment. New York: McGraw-Hill.

Costa, P., \& McRae, R. (1985). The NEO personality inventory manual. Odessa, FL: Psychological Assessment Resource.

Darlington, R. B. (1968). Multiple regression in psychological research and practice. Psychological Bulletin, 69, 161-182.

Erickson, M., Sroufe, L., \& Egeland, B. (1985). The relationship between quality of attachment and behavior problems in preschool in a high-risk sample. In I. Bretherton \& E. Waters (Eds.), Growing points of attachment theory and research. Monographs of the Society for Research in Child Development, 50(1-2, Serial No. 209, pp. 147-166).

Fagot, B. I., \& Kavanagh, K. (1990). The prediction of antisocial behavior from avoidant attachment classification. Child Development, 61, 864-873.

Furstenberg, F. , Cook, T., Eccles, J., Elder, G., \& Sameroff, A. (1999). Managing to make it. Urban families and adolescent success. Chicago: University of Chicago Press.

Goldberg, S., Gotowiec, A., \& Simmons, R. J. (1995).
Infant-mother attachment and behavior problems in healthy and chronically ill preschoolers. Development and Psychopathology, 7, 267-282.

Greenberg, M. T. (1999). Attachment and psychopathology in childhood. In J. Cassidy \& P. R. Shaver (Eds.), Handbook of attachment: Theory, research and clinical applications (pp. 469-496). New York: Guilford Press.

Hamilton, C. (2000). Continuity and discontinuity of attachment from infancy through adolescence. Child Development, 71, 690-694.

Hogan, A. E., Scott, K. G., \& Bauer, C. R. (1992). The Adaptive Social Behavior Inventory (ASBI): A new assessment of social competence in high risk threeyear-olds. Journal of Psychoeducational Assessment, 10, 230-239.

Lewis, M., Feiring, C., McGuffog, C., \& Jaskir, J. (1984). Predicting psychopathology in six-year-olds from early social relations. Child Development, 55, 123136.

Liaw, F., \& Brooks-Gunn, J. (1994). Cumulative familial risks and low-birthweight children's cognitive and behavioral development. Journal of Clinical Child Psychology, 23, 360-372.

Luster, T., \& McAdoo, H. (1994). Factors related to the achievement and adjustment of young African-American children. Child Development, 66, 1080-1094.

Lyons-Ruth, K., Alpern, L., \& Repacholi, B. (1993). Disorganized infant attachment classification and maternal psychosocial problems as predictors of hostileaggressive behavior in the preschool classroom. Child Development, 64, 572-585.

Lyons-Ruth, K., \& Jacobvitz, D. (1999). Attachment disorganization. In J. Cassidy \& P. R. Shaver (Eds.), Handbook of attachment: Theory, research and clinical applications (pp. 520-554). New York: Guilford Press.

Marshall, N. L., \& Barnett, R. C. (1991). Race and class and multiple role strains and gains among women employed in the service sector. Women and Health, 17, $1-19$.

Munson, J., McMahon, R., \& Spieker, S. (2001). Structure and variability in the developmental trajectory of children's externalizing problems: Impact of infant attachment, maternal depressive symptomology, and child sex. Developmental and Psychopathology, 13, 277-296.

NICHD Early Child Care Research Network. (1997). The effects of infant child care on infant-mother attachment security: Results of the NICHD study of early child care. Child Development, 68, 860-879.

NICHD Early Child Care Research Network. (1998). Early child care and self-control, compliance, and problem behavior at 24 and 36 months. Child Development, 69, 1145-1170.

Pungello, E., Kupersmidt, J., Burchinal, M., \& Patterson, C. (1996). Environmental risk factors and children's achievement from middle childhood to early adolescence. Developmental Psychology, 32, 755-767.

Radloff, L. (1977). The CES-D scale. A self report depression scale for research in the general population. Applied Psychological Measurement, 1, 385-410.

Renken, B., Egeland, B., Marvinney, D., Sroufe, L., \& Mangelsdorf, S. (1989). Early childhood antecedents of aggression and passive withdrawal in early elementary school. Journal of Personality, 57, 257-282.

Reynell, J. (1991). Reynell Developmental Language 
Scales (U.S. edition). Los Angeles: Western Psychological Service.

Rutter, M. (1979). Protective factors in children's responses to stress and disadvantage. In M. W. Kent \& J. E. Rolf (Eds.), Primary prevention of psychopathology (Vol. 3, pp. 49-74). Hanover, NH: University Press of New England.

Rutter, M. (2000). Psychosocial influences: Critiques, findings, and research needs. Development and Psychopathology, 12, 375-406.

Rutter, M., \& Sroufe, L. A. (2000). Developmental psychopathology: Concepts and challenges. Development and Psychopathology, 12, 265-296.

Rutter, M., Cox, A., Tupling, C., Berger, M., \& Yule, W. (1975). Attainment and adjustment in two geographical areas: 1 . The prevalence of psychiatric disorder British Journal of Psychiatry, 126, 493-509.

Sameroff, A. (2000). Developmental systems and psychopathology. Development and Psychopathology, 12, 297-312.

Sameroff, A. J., Bartko, W., Baldwin, A., Baldwin, C., \& Seifer, R. (1998). Family and social influences on the development of child competence. In M. Lewis \& C. Feiring (Eds.), Families, risk, and competence. Mahwah, NJ: Erlbaum.

Sameroff, A., Seifer, R., Baldwin, A., \& Baldwin, C. (1993). Stability of intelligence from preschool to adolescence: The influence of social and family risk factors. Child Development, 64, 80-97.

Sameroff, A. J., Seifer, R., Zax, M., \& Barocas, R. (1987). Early indicators of developmental risk: Rochester longitudinal study. Schizophrenia Bulletin, 13, 383-394.

Schaefer, M., \& Olson, D. (1981). Assessing intimacy: The PAIR inventory. Journal of Marital and Family Therapy, 7, 640-653.

Shaw, D. S., Owens, E. B., Vondra, J. I., Keenan, K., \& Winslow, E. B. (1996). Early risk factors and pathways in the development of early disruptive behavior problems. Development and Psychopathology, 8, 679-699.

Shaw, D., \& Vondra, J. (1995). Infant attachment security and maternal predictors of early behavior problems: A longitudinal study of low-income families. Journal of Abnormal Child Psychology, 23, 335-357.

Sroufe, L. A. (1988). The role of infant-caregiver attachment in development. In J. Belsky \& T. Nezworski (Eds.), Clinical implications of attachment (pp. 1840). Hillsdale, NJ: Erlbaum.

Sroufe, L. A., Carlson, E., Levy, A., \& Egeland, B. (1999). Implications of attachment theory for developmental psychopathology. Development and Psychopathology, 11, 1-13.

Troy, M., \& Sroufe, L. A. (1987). Victimization among preschoolers: Role of attachment relationship history. Journal of the American Academy of Child and Adolescent Psychiatry, 26, 166-172.

van Ijzendoorn, M., Dijkstra, J., \& Bus, A. (1995). Attachment, intelligence, and language: A meta-analysis. Social Development, 4, 115-128.

van Ijzendoorn, M. H., Goldberg, S., Kroonenberg, P. M., \& Frenkel, O. J. (1992). The relative effects of maternal and child problems on the quality of attachment: A meta-analysis of attachment in clinical samples. Child Development, 63, 147-156.

van Ijzendoorn, M. H., \& Kroonenberg, P. M. (1988). Cross-cultural patterns of attachment: A meta-analysis of the strange situation. Child Development, 59, 147-156.

Waters, E., Merrick, S., Treboux, D., Crowell, J., \& Albersheim, L. (2000). Attachment security in infancy and early adulthood: A 20-year longitudinal study. Child Development, 71, 684-689.

Weinfield, N., Sroufe, L. A., \& Egeland, B. (2000). Attachment from infancy to early adulthood in a highrisk sample: Continuity, discontinuity, and their correlates. Child Development, 71, 695-702. 